\title{
Thermal Performance Evaluation and Modeling of Parameters for Optimum Fuel Consumption of the Diesel Fired Furnace
}

\author{
Ameya Deshpande* and S. V. Dingare \\ †Department of Mechanical Engineering, Savitribai Phule Pune University, MIT College of Engineering, Pune, India
}

Accepted 15 June 2016, Available online 20 June 2016, Special Issue-5 (June 2016)

\begin{abstract}
The diesel fired furnace is being used to melt the alkaline salts. These melted salts are then treated to form granular of particular shapes. Such are then used for the process of purification of molten aluminum. The major energy consumption is from the furnace throughout the process. The furnace has the maximum heat transfer capacity being indicated by the parameters of the furnace. Hence it is necessary to study the relationship between operational conditions which can affect the furnace efficiency. The experimental study is carried out on the furnace involving critical parameters namely melting rate, furnace temperature, flue gas temperature, preheated air temperature and fuel consumption. The regression models are created to capture the combine effect of such parameters. These models are tested for root mean squared variation and the statistical parameters called $R^{2}$, adjusted $R^{2}$. It is found that the furnace runs optimum at the particular frequency of the input material with melting rate giving maximum efficiency. The regression models created are well approximated with the experimental data giving lesser mean average variation. This shows that the regression models are capable of capturing the combined effect of parameters and their function.
\end{abstract}

Keywords: Thermal performance, $R^{2}$, Regression modeling, High Speed Diesel (HSD) oil, Flue gas.

\section{Introduction}

The furnace is used as an efficient way of heat transfer in converting mixture of in-organic salts into fuse flux which are used for purification of aluminum. The concept of the furnace evolves around heat transfer by both radiation and convection by combustion of air and fuel. The heat generated by the combustion is used to heat the crucible inside which in turns melts the salts to form eutectic compounds as fused fluxes.

The process of combustion involves controlled flow of the diesel by the pump under the specified pressure and through the burner. The fuel to air ratio is controlled by air blower and the dampers. The incoming air is pre-heated by the recuperation by way of heat transfer from the flue gases generated by burning of diesel. The use of recuperation reduces the consumption of diesel by way of heated air giving more input energy and raising the maximum flame temperature. The design of the furnace involves critical parameter like nozzle design, fuel pressure, flow of the heated air etc. The other factors in designing influence the insulation, the thickness and the quality.

When the crucible is empty and the process has to start, the burner is ignited by way of electric current. The flow rate of fuel is controlled by the different sizes

*Corresponding author: Ameya Deshpande of nozzle in the burner. The burners are well recognized by their turn-down ratio. Flow rate incorporates the important role as to maintain the temperature of the furnace. The melting rate is higher in the case of diesel fired furnace than the conventional electrical furnaces. Hence it is important to maintain the process parameters at the optimum level minimizing the specific energy and fuel consumption.

(Singh R., et al, 2000) has carried out the study on oil fired furnace and the effect of air-preheating and excess air is stated for the performance. (Singh R., et al, 2000) has carried out study of the critical parameters for the pollution free casting in the cupola furnace. The furnace has the optimum point in terms of efficiency, below which if it is operated gives lesser output and beyond which if it is operated consumes more fuel because the heat transfer limitations are reached. This effect is stated by the measure of the parameter $\mathrm{R}$ ( $\mathrm{kg} / \mathrm{lit}$ ) in the study which is the ratio of output of the furnace (product) to the input fuel consumed.

Regression techniques have a long history of use as forecasting tools in multiple disciplines. Regression models have the advantage of simple computation and easy implementation. Regression models are also used for predicting the relationship between the critical parameters of such furnaces (Ranjit Singh, et al, 2010). (R. K. Jain, 2011) also developed practical regression model capturing the complex function of critical input 
parameters to specific fuel consumption and found well correlated with the experimental data. (Veerendra Singh, et al, 2007) carried out the statistical inferential analysis to predict the performance of arc furnace taking various combinations of input raw materials. The regression model is developed firstly followed by the other artificial neural network models. The comparison is made by the measure of correlation coefficient. (Douglas C. Montgomery, et al, 2014) has given the regression models in the matrix form suitable for coding languages like MATLAB. It is also referred for the various model building techniques and taking inferences. The hypothesis tests and importance of the confidence intervals of the regression coefficients is stated for the multiple linear regression.

\section{The salt melting process}

The process of the salt melting is done in the furnace. The salts being melted are alkaline in nature. These are then used in the purification of the molten aluminum. The process consists of input raw material of different standards. It is also noted that the input raw material has a significant effect on energy consumption and hence on consumption of the fuel. The salts are driven in on a screw conveyer by the variable frequency drive (VFD). The process is continuous and the heat is in steady state. The incoming salts are melted in the inner cylindrical shell containing molten bath of salts. The molten liquid is poured out of the furnace by a conical passage. Hence the liquid is poured under the force of gravity. The main reason behind the outgoing melting rate is the action of buoyancy. The salts have greater density than the density of the molten bath. Hence the displaced volume of solids coming in replaces by the volume of liquid pouring out and the molten liquid comes out of the furnace.

It is necessary to maintain the core temperature of the molten bath at a constant value because the process is continuous. Hence as the input salt rate increases the extra amount of heat energy is needed to keep the temperature constant. Hence the incremental amount of fuel as well as air has to be added for each disturbance from the equilibrium condition. While doing so the other parameters change like the temperature at various parts.

\section{Experimental setup and procedure}

\subsection{Experimental setup}

The diesel fired furnace at the facility of the company at PUNE is used for the experimentation. The furnace has the crucible made up of ceramic material of diameter $780 \mathrm{~mm}$. The crucible is based on the base leg of $500 \mathrm{~mm}$ diameter and has the total height of 900 $\mathrm{mm}$ as shown in the Fig. No.1. It has the conical passage for pouring out the liquid with the length of $530 \mathrm{~mm}$ and slant edge of $570 \mathrm{~mm}$.

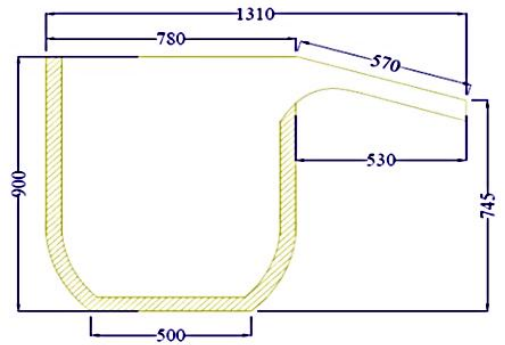

Fig.1 The heating crucible (all dimensions are in $\mathrm{mm}$.

It is the single burner furnace as shown in Fig. 2 with the maximum turn-down ratio of 5.0. It has the single flame placed tangentially to the crucible. The fuel is pressurized by the oil pump shown in Fig. 2 to the burner. The furnace has the insulation layer varying from inner to outer diameters. The inner most lining is of aluminum of the inner diameter $930 \mathrm{~mm}$ with the thickness of $115 \mathrm{~mm}$ as shown in the Fig. No.4. It is followed by fire brick lining of $75 \mathrm{~mm}$ thickness of inner diameter of $1160 \mathrm{~mm}$. The hot and cold face lining are in series co-central of $75 \mathrm{~mm}$ thickness. The most outer furnace shell base brick lining is of 1730 mm diameter.

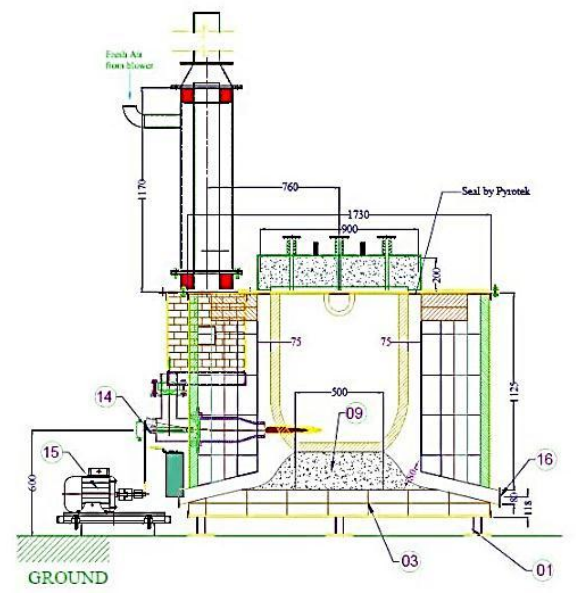

Fig.2 Furnace front view (all dimensions are in mm.)

The furnace is equipped with the recuperator which is the double pipe heat exchanger as shown in the Fig. No.3. Flow in the tube consist of high temperature flue gases while in the annulus flows the ambient air. The length and hence the overall area available for heat transfer is lower. The flue gases are fed to the chimney by the chimney pipe of total height of $2448 \mathrm{~mm}$. The furnace has the fresh air blower, the outlet of which is attached to the burner. The incoming solid salts are fed into the furnace by the Variable Frequency Drive (V.F.D.). The frequency of the drive can be adjusted by the operator and has the range varying from 10 to 30 $\mathrm{Hz}$ by the inputs to the control panel. The crucible has the lid of the diameter of $930 \mathrm{~mm}$ shown in Fig. 4 which has the openings for thermocouple and for the agitator shaft of inclined plates. The furnace temperature is the measure of the temperature of the gap between the crucible and aluminum lining at this 
opening. The flue gas temperature and preheated air temperature are the measure of the temperatures of the centerline of the respective pipes. All the thermocouples are of K-type with only distinction of sheathed end for the temperature measurement of the molten salts.

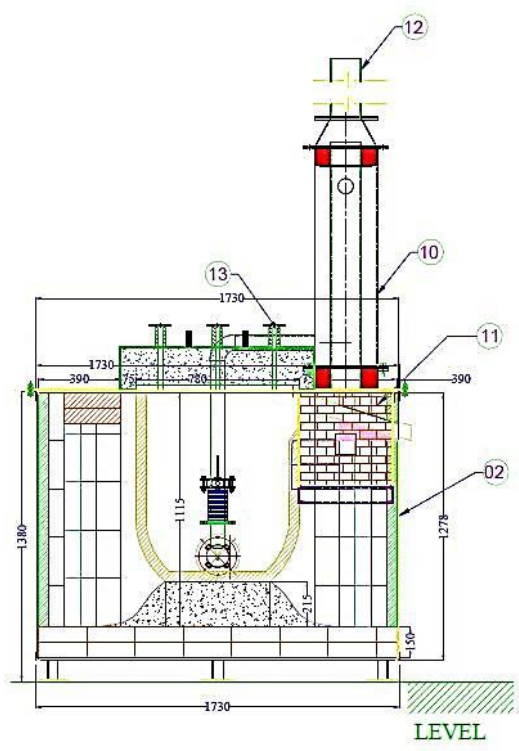

Fig.3 Furnace side view (all dimensions are in $\mathrm{mm}$. )

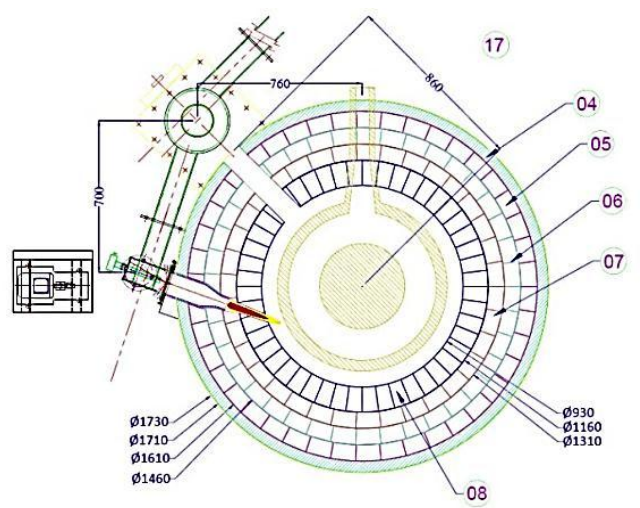

Fig.4 Furnace top view (all dimensions are in $\mathrm{mm}$.)

Table 1 Table of contents

\begin{tabular}{|c|c|c|}
\hline Sr. No. & Description & Quantity \\
\hline 01 & Base support leg & 01 \\
\hline 02 & Furnace shell & 01 \\
\hline 03 & Base brick lining $150 \mathrm{~mm}$ & 01 \\
\hline 04 & Calcium silicate board $50 \mathrm{~mm}$ & 01 \\
\hline 05 & Cold face lining 75 mm & 01 \\
\hline 06 & Hot face lining 75 mm & 01 \\
\hline 07 & Fire break lining 75 mm & 01 \\
\hline 08 & Aluminim lining $115 \mathrm{~mm}$ & 01 \\
\hline 09 & Castable base & 01 \\
\hline 10 & Recuperator & 01 \\
\hline 11 & Chimney box & 01 \\
\hline 12 & Chimeny pipe & 01 \\
\hline 13 & Air piping & 01 \\
\hline 14 & Burner (dual) & 01 \\
\hline 15 & Oil pump & 01 \\
\hline 16 & Drain hole & 02 \\
\hline 17 & Fresh air from blower & 01 \\
\hline
\end{tabular}

\subsection{Experimental procedure}

The runs are carried out by varying the frequency of the V.F.D. It is done by the input to the control panel. Equilibrium in the process is by maintaining the liquid temperature to the particular value which is $487^{\circ} \mathrm{C}$. The value is taken by the recommendation of the operators. Hence each run is the disturbance produce to the equilibrium. For the increased amount of input material the increased heat has to be given to the crucible. Then the fuel pressure is increased by the key at the pressure gauge. The optimum air required is set by controlling the valve manually. The increased fuel pressure increases the flow rate of fuel hence the furnace temperature. Furnace temperature is the indication of the heat available at the furnace. The changes in the fuel pressure are done until the liquid temperature is again maintained at $487^{\circ} \mathrm{C}$. The process is repeated for several frequencies initializing from 10 $\mathrm{Hz}$ to the maximum possible until the process is not maintained to equilibrium or the limitation of V.F.D. is reached. The process is terminated at $25 \mathrm{~Hz}$ frequency because of the former reason.

The reading of furnace, flue gas, preheated air temperature is reported manually. The melting rate is measured by allowing the liquid to pour into the metal flask for 1 minute for every equilibrium condition. Then the metal flask is weighed on the weighing balance. The measurement protocol is developed for the measurement of the fuel flow rate. Only the pressure rating is reported at the time of runs and later at the day of maintenance the flow rate is measured setting at the different pressure levels. The volumetric beaker is used to measure the flow rate of I minute. The minimum increment of reading of the volumetric beaker is $5 \mathrm{ml}$.

\section{Data reduction}

For the thermal performance evaluation the principle equations of mass and energy balance are applied (S. M. Vora et al, 2008). The excess air is taken between 30 to $40 \%$.

\subsection{Mass balance}

The total mass rate fed to the burner is the sum of mass of fuel and mass of air. Mass of fuel is determined by

$m_{\text {fuel }}=\rho_{\text {fuel }} \times v_{\text {fuel }}$

where $m_{\text {fuel }}$ is the mass flow rate of the fuel $(\mathrm{kg} / \mathrm{h})$, $\rho_{\text {fuel }}$ is the density of the fuel which is $0.820 \mathrm{~kg} / \mathrm{lit}$ and $v_{f u e l}$ is the volume flow rate of the fuel (lit/h). Then the total mass flow rate fed in is

mtotal $=$ mair + mfuel

where $m$ total shows the total mass flow rate $(\mathrm{kg} / \mathrm{h})$. Then the mass of flue gas mflue is equal to the total mass added into the furnace. 


\subsection{Energy balance}

The total energy input to the furnace is the energy of the fuel and energy of the preheated air.

$Q_{\text {total }}=Q_{\text {fuel }}+Q_{\text {air }}$

where $Q_{\text {total }}(\mathrm{kJ} / \mathrm{h})$ is the total input heat energy, $Q_{\text {fuel }}$ $(\mathrm{kJ} / \mathrm{h})$ is the fuel heat energy and $Q_{\text {air }}(\mathrm{kJ} / \mathrm{h})$ is the input heat energy of preheated air.

$Q_{\text {fuel }}=m_{\text {fuel }} \times C . V \cdot$ fuel

where $C . V_{\text {.fuel }}(\mathrm{kJ} / \mathrm{kg})$ is the net calorific value of HSD.

$Q_{\text {air }}=$ mair $\times$ Cair $\times($ Tair - Tamb. $)$

where Cair is the specific heat capacity of air taken at ${ }^{65}{ }^{\circ} \mathrm{C}$ which is $1.008(\mathrm{~kJ} / \mathrm{kg} \mathrm{K})$ and $T_{\text {air }}\left({ }^{\circ} \mathrm{C}\right)$ is the preheated air temperature, $T_{a m b}\left({ }^{\circ} \mathrm{C}\right)$ is the ambient air temperature which is taken as $25^{\circ} \mathrm{C}$. The heat loss in flue gases is calculated by

$$
Q_{\text {flue }}=m \text { flue } \times \text { Cflue } \times\left(T_{\text {flue }}-T_{\text {amb }}\right)
$$

where $Q_{\text {flue }}$ is the amount of heat lost in the flue gases, Cflue is the specific heat capacity of the flue gases, $T$ flue $\left({ }^{\circ} \mathrm{C}\right)$ is the temperature of the flue gases. The total heat loss is the sum of the heat lost in the flue gases and the other unaccounted heat loss like radiation loss, heat lost from the lining and wall structure to the atmosphere. The total heat loss is calculated as

Qloss $=(1-\eta) \times Q$ total

where $\eta$ is the efficiency of the furnace and $Q_{\text {loss }}$ $(\mathrm{kJ} / \mathrm{h})$ is the total heat energy loss. Efficiency is calculated as

$$
\eta=\frac{Q_{\text {salt }}}{Q_{\text {total }}}
$$

where $Q$ salt is the heat required to melt the salt $(\mathrm{kJ} / \mathrm{h})$.

$$
Q \text { salt }=m s a l t \times h v s a l t
$$

where msalt is the melting rate $(\mathrm{kg} / \mathrm{h})$ and $h v_{\text {salt }}$ is the heating value of the salt $(\mathrm{kJ} / \mathrm{kg})$ including sensible and latent heat value. It is directly given by the facility.

\section{Model Design}

Regression modeling is done by using the melting rate, furnace temperature, flue gas temperature, preheated air temperature as input parameters and fuel consumption as output parameter. The two models are considered. The first model only takes the linear relationship while the second model is nonlinear in parameters.

\subsection{Linear Model}

In this model all the critical input parameters of the furnace are taken as a linear function of the output parameter. The model is linear in terms of coefficients of these parameters. The approximated equation is

$Y_{1}=b_{0}+b_{1} \times x_{1}+b_{2} \times x_{2}+b_{3} \times x_{3}+b_{4} \times x_{4}$

where $Y_{1}$ is the modeled specific fuel consumption of the model 1 and $x_{1}, x_{2}, x_{3}, x_{4}$ are melting rate furnace temperature, flue gas temperature, preheated air temperature respectively. $b_{0}, b_{1}, b_{2}, b_{3}, b_{4}$ are the respective coefficient of the parameters. As this model is linear it is solved directly by using least square method in MATLAB 13.0 code.

\subsection{Non-linear Model}

In this model the output parameter is taken as a nonlinear function of input parameters. Such models are called intrinsically linear models because they can be transformed into linear form by some mathematical operations. Hence the model is first transformed to a linear model by using natural log and then it is solved by least square method in MATLAB 13.0 code. The function is approximated as

$$
Y_{2}=C_{0} \times X 1^{C 1} \times X 2^{C 2} \times X 3^{C 4} \times X 4^{C 4}
$$

where $Y_{2}$ is the modeled specific fuel consumption of the model 2 and $C_{0}, C_{1}, C_{2}, C_{3}, C_{4}$ are the respective coefficient of the parameters. Both the models are tested by the statistical measures namely $\mathrm{R}^{2}$, adjusted $\mathrm{R}^{2}$ and root mean squared variation of residuals.

\section{Results and observation}

\subsection{Thermal performance evaluation}

The thermal performance of the furnace is evaluated by the measures of efficiency and hence the total loss at every run or frequency. The melting rate $(\mathrm{kg} / \mathrm{h})$ and fuel consumption (lit/h) is shown along with the ratio $\mathrm{R}$ (kg/lit) for each run in Table 2 . The significance of $\mathrm{R}$ is discussed in the later section. The data is collected and reduced to the percentage form of the total input energy is shown in the Table 3 . The calculations are 
done using Eq. (1) to (9) where the values taken are experimental. The ration $\mathrm{R}(\mathrm{kg} / \mathrm{lit})$ is the measure of the kg of output after the combustion of one liter HSD.

Table 2 Experimental data

\begin{tabular}{|c|c|c|c|}
\hline Frequency & $\begin{array}{c}\text { Melting rate } \\
\mathrm{kg} / \mathrm{h}\end{array}$ & $\begin{array}{c}\text { Fuel consumption } \\
\text { lit./h }\end{array}$ & $\begin{array}{c}\text { Ratio } \\
\mathrm{R} \mathrm{kg} / \mathrm{lit}\end{array}$ \\
\hline 10 & 192.00 & 9.30 & 20.65 \\
\hline 11 & 205.00 & 9.75 & 21.03 \\
\hline 12 & 205.00 & 9.30 & 22.04 \\
\hline 13 & 236.25 & 10.30 & 22.94 \\
\hline 14 & 270.25 & 11.50 & 23.50 \\
\hline 15 & 306.18 & 12.60 & 24.30 \\
\hline 16 & 322.50 & 12.90 & 25.00 \\
\hline 17 & 345.84 & 13.20 & 26.20 \\
\hline 18 & 378.12 & 13.80 & 27.40 \\
\hline 19 & 390.57 & 14.10 & 27.70 \\
\hline 20 & 421.50 & 14.70 & 28.67 \\
\hline 21 & 430.50 & 15.00 & 28.70 \\
\hline 22 & 439.50 & 15.00 & 29.30 \\
\hline 23 & 448.29 & 15.30 & 29.30 \\
\hline 24 & 451.38 & 15.70 & 28.75 \\
\hline 25 & 451.55 & 15.70 & 28.76 \\
\hline
\end{tabular}

Table 3 Thermal performance of the furnace

\begin{tabular}{|c|c|c|c|c|}
\hline $\begin{array}{c}\text { Frequency } \\
\mathrm{Hz}\end{array}$ & $\begin{array}{c}\text { Efficienc } \\
\mathrm{y}(\%)\end{array}$ & $\begin{array}{c}\text { Flue gas } \\
\text { Loss. (\%) }\end{array}$ & $\begin{array}{c}\text { Total } \\
\text { Loss. (\%) }\end{array}$ & $\begin{array}{c}\text { Other } \\
\text { Loss } \\
(\%)\end{array}$ \\
\hline 10 & 35.16 & 37.79 & 64.84 & 27.05 \\
\hline 11 & 35.81 & 37.97 & 64.19 & 26.22 \\
\hline 12 & 37.55 & 38.02 & 62.45 & 24.42 \\
\hline 13 & 39.05 & 38.22 & 60.95 & 22.73 \\
\hline 14 & 40.00 & 38.37 & 60.00 & 21.63 \\
\hline 15 & 41.35 & 38.27 & 58.65 & 20.38 \\
\hline 16 & 42.51 & 38.10 & 57.49 & 19.39 \\
\hline 17 & 44.53 & 37.97 & 55.47 & 17.50 \\
\hline 18 & 46.55 & 37.80 & 53.45 & 15.65 \\
\hline 19 & 47.04 & 37.68 & 52.96 & 15.28 \\
\hline 20 & 48.67 & 37.61 & 51.33 & 13.71 \\
\hline 21 & 48.70 & 37.67 & 51.30 & 13.63 \\
\hline 22 & 49.72 & 37.74 & 50.28 & 12.54 \\
\hline 23 & 49.70 & 37.92 & 50.30 & 12.38 \\
\hline 24 & 48.76 & 38.06 & 51.24 & 13.18 \\
\hline 25 & 48.77 & 38.16 & 51.23 & 13.07 \\
\hline
\end{tabular}

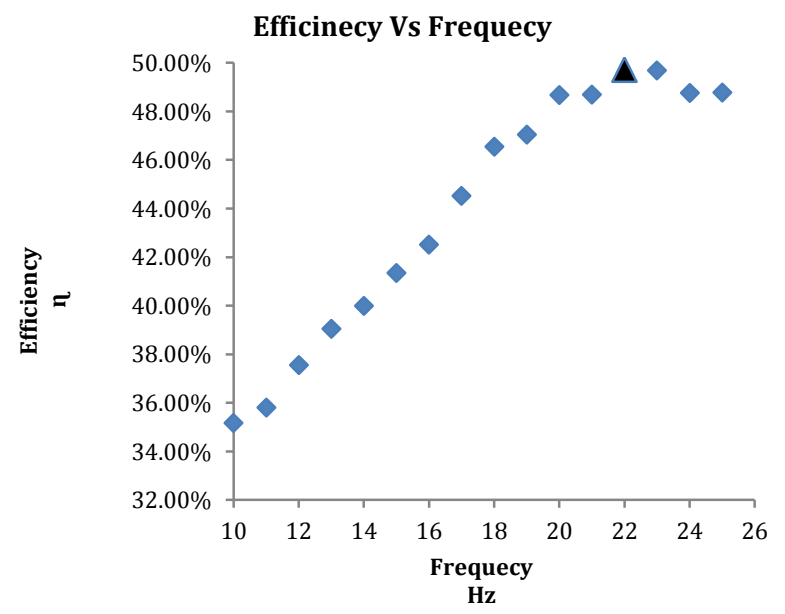

Fig.5 Efficiency Vs Frequency graph with maximum efficiency (triangular shape)

\subsection{Critical observations}

The melting rate is increasing from lower to higher frequency. This is accompanied by the increase in ratio $\mathrm{R}$ (kg/lit.). This implies the utilization of heat for the incoming material (salts). This also implies the scope of adding more energy to the salt as that result in increased melting rate from the furnace. The efficiency is lower for the lower frequency and the total loss hence the other loss is also higher. But as the frequency increases the efficiency increases shown in Fig 5. The total loss is decreasing and is least for $22 \mathrm{~Hz}$ frequency although the ratio $\mathrm{R}(29.30 \mathrm{~kg} / \mathrm{lit}$.) is being same for both 22 and $23 \mathrm{~Hz}$. This shows the maximum limit of heat transfer is reached for this particular furnace at $22 \mathrm{~Hz}$ frequency of incoming material and at that particular melting rate $(439.50 \mathrm{~kg} / \mathrm{hr})$.

\subsection{Regression model evaluation}

The coefficient of both the models $Y_{1}$ and $Y_{2}$ are determined by using MATLAB 13.0 codes. The method used is linear least squared with transformed linear method for model $Y_{2}$. The matrix form of both the coefficients is shown below. By using Eq. (10), (11), (12) and (13) the modeled fuel consumption is shown in Table 4 for $Y_{1}$ and Table 5 for $Y_{2}$. The summary is made in the last row of the respective tables where the value of $\mathrm{R}^{2}$, adjusted $\mathrm{R}^{2}$ along with root mean squared variation is shown. The importance of these parameters is discussed in the statistical observation. The inference from the data is with the help of such parameters. The model with the higher values of $\mathrm{R}^{2}$ and adjusted $\mathrm{R}^{2}$ is optimized with minimum root mean squared variation.

$$
\left[\begin{array}{l}
b_{0} \\
b_{1} \\
b_{2} \\
b_{3} \\
b_{4}
\end{array}\right]=\left[\begin{array}{l}
-2.3959 \\
+0.0193 \\
+0.0289 \\
-0.0095 \\
-0.0208
\end{array}\right]
$$

$$
\left[\begin{array}{l}
C_{0} \\
C_{1} \\
C_{2} \\
C_{3} \\
C_{4}
\end{array}\right]=\left[\begin{array}{l}
6.0477 e-04 \\
+0.4798 \\
+1.9676 \\
-0.4140 \\
-0.8927
\end{array}\right]
$$

Table 4 Modeled fuel consumption $Y_{1}$

\begin{tabular}{|c|c|c|c|}
\hline $\begin{array}{c}\text { Frequency } \\
\mathrm{Hz}\end{array}$ & $\begin{array}{c}\text { Actual fuel } \\
\text { consumption } \\
\text { lit. }\end{array}$ & $\begin{array}{c}\text { Modeled fuel } \\
\text { consumption } \\
Y 1 \text { lit. }\end{array}$ & $\begin{array}{c}\text { Variation } \\
\text { lit. }\end{array}$ \\
\hline 10 & 9.30 & 9.1621 & 0.1379 \\
\hline 11 & 9.75 & 9.7579 & -0.0079 \\
\hline 12 & 9.30 & 9.5687 & -0.2687 \\
\hline 13 & 10.30 & 10.4588 & -0.1588 \\
\hline 14 & 11.50 & 11.4216 & 0.0784 \\
\hline 15 & 12.60 & 12.5952 & 0.0048 \\
\hline
\end{tabular}




\begin{tabular}{|l|l|l|l|}
\hline 16 & 12.90 & 12.7103 & 0.1897 \\
\hline 17 & 13.20 & 13.0828 & 0.1172 \\
\hline 18 & 13.80 & 13.6048 & 0.1952 \\
\hline 19 & 14.10 & 14.0583 & 0.0417 \\
\hline 20 & 14.70 & 14.6513 & 0.0487 \\
\hline 21 & 15.00 & 14.9639 & 0.0361 \\
\hline 22 & 15.00 & 15.2978 & -0.2978 \\
\hline 23 & 15.30 & 15.5138 & -0.2138 \\
\hline 24 & 15.70 & 15.672 & 0.0280 \\
\hline 25 & 15.70 & 15.6306 & 0.0694 \\
\hline \multicolumn{4}{|c|}{$\mathrm{R}^{2}=0.9956$} \\
\hline \multicolumn{4}{|c|}{ Rodjusted $\mathrm{R}^{2}=0.9940$} \\
\hline
\end{tabular}

\section{Conclusions}

By the thermal performance evaluation the efficiency as well as the optimum melting capacity has come to know. The regression modeling helps in understanding and approximating the complex relationship between output and critical input parameters. The following conclusions are made.

1) The ratio $\mathrm{R}$ (kg/lit.) of melting rate to fuel consumption is highest for two frequencies 22 and $23 \mathrm{~Hz}$ of incoming material.

2) Ratio $\mathrm{R}(\mathrm{kg} / \mathrm{lit}$.) is increased by $17.2 \%$ over the melting rate of $322.50 \mathrm{~kg} / \mathrm{h}$ which is the average operating rate of the furnace at the plant.

Table 5 Modeled fuel consumption $Y_{2}$

\begin{tabular}{|c|c|c|c|}
\hline $\begin{array}{c}\text { Frequency } \\
\mathrm{Hz}\end{array}$ & $\begin{array}{c}\text { Actual fuel } \\
\text { consumptionlit } \\
\cdot\end{array}$ & $\begin{array}{c}\text { Modeled fuel } \\
\text { consumption } \\
Y 2 \text { lit. }\end{array}$ & $\begin{array}{c}\text { Variation } \\
\text { lit. }\end{array}$ \\
\hline 10 & 9.30 & 9.1499 & 0.15012 \\
\hline 11 & 9.75 & 9.6912 & 0.05881 \\
\hline 12 & 9.30 & 9.5389 & -0.23888 \\
\hline 13 & 10.30 & 10.4545 & -0.15452 \\
\hline 14 & 11.50 & 11.4193 & 0.08068 \\
\hline 15 & 12.60 & 12.5767 & 0.02326 \\
\hline 16 & 12.90 & 12.7468 & 0.15318 \\
\hline 17 & 13.20 & 13.1448 & 0.05522 \\
\hline 18 & 13.80 & 13.6538 & 0.14619 \\
\hline 19 & 14.10 & 14.1065 & -0.00645 \\
\hline 20 & 14.70 & 14.6578 & 0.0422 \\
\hline 21 & 15.00 & 14.9724 & 0.02764 \\
\hline 22 & 15.00 & 15.2857 & -0.28571 \\
\hline 23 & 15.30 & 9.1499 & 0.15012 \\
\hline 24 & 15.70 & 9.6912 & 0.05881 \\
\hline 25 & 15.70 & 9.5389 & -0.23888 \\
\hline \multicolumn{4}{|c}{$\mathrm{R}^{2}=0.9961$} \\
adjusted $\mathrm{R}^{2}=0.9950$ \\
\hline \multicolumn{5}{|c}{ Root mean squared variation $=0.0137$ lit. } \\
\hline
\end{tabular}

\subsection{Statistical observations}

The modeled fuel consumption $Y_{1}$ and $Y_{2}$ are in well match with their actual variation. The measure of this match is the respective $\mathrm{R}^{2}$. The $\mathrm{R}^{2}$ for $Y_{1}$ is lower than $Y_{2}$ by a few margins. But the root mean square variation is marginal being 0.1799 for $Y_{1}$ and 0.0137 for $Y_{2}$. This can be explained by the adjusted $\mathrm{R}^{2}$ which is higher for $Y_{2}$. This is because the addition of terms (or the form of equation in this case) is reflected in adjusted $\mathrm{R}^{2}$ as it tends to reduce the error with the addition of new terms (or the form of equation in this case). Hence the model with lower root mean squared variation $\left(Y_{2}\right)$ is preferred.

3) The efficiency is maximum at the melting rate of $439.50 \mathrm{~kg} / \mathrm{h}$ with an increase of $16.9 \%$ over the average operating frequency of $16 \mathrm{~Hz}$ of incoming material.

4) The flue gas losses are least at $22 \mathrm{~Hz}$ but the other losses are least at $23 \mathrm{~Hz}$ of frequency of incoming material. This indicates radiation heat transfer at higher temperature.

5) Regression models are capable of approximating the complex relationship between critical parameters of the furnace.

6) The non-linear (intrinsically linear) models are better giving root mean squared variation below \pm $10 \%$.

7) The adjusted $R^{2}$ is affected only by the form of the equation keeping the regressors constant.

\section{References}

Ranjit Singh, Puroshotam Kumar, (2010), Neural Networks and Regression Modeling of Eco-friendly Melting Furnace Parameters using Bio-fuels, International Journal of Computer Applications, Volume 43- No.1.

Veerendra Singh, S. Mohan Rao, K.S. Raju, (2007), predicting the performance of submerged arc furnace with varied raw material combinations using artificial neural network, Journal of Materials Processing Technology, 111-116.

Singh R., Patvardhan C., Jain R. K. and A. Kumar, (2000). Economic Justification of Coke-less Cupola for Pollution Free Casting in Indian Environment with Special Reference to Agra Indian Foundry Journal, Vol. 46, No. 8, pp. 18-27

Singh R., Patvardhan C., Jain R. K. and A. Kumar, (2000). Effect of Air - Preheating and Excess Air on the Performance of LDO Fired Rotary Furnace Indian Foundry Journal, Vol. 46, No. 11 , pp. 26-32.

R. K. Jain, 2011, Modeling, Optimization and Simulation of input parameters for optimum specific fuel (energy) consumption of LDO fired Rotary furnace, International Journal Of Applied Engineering Research Volume 2, No 1.

Douglas C. Montgomery, (2014), WILEY publications, Third edition.

S.M. Vora, (2008), Stoichiometry, Tata macgraw hill, $4^{\text {thedition }}$ 